\title{
Labirintos da inclusão: a medicalização como prática perversa na educação
}

\author{
lasmim Santos Silva ${ }^{1}$ \\ Helena de Almeida Cardoso Caversan ${ }^{2}$ \\ Kelly Naiara Soares de Souza Santos ${ }^{3}$ \\ Miguel Levi de Oliveira Lucas ${ }^{4}$ \\ Thauany Duarte Diniz ${ }^{5}$ \\ Renata Gonçalves de Melo ${ }^{6}$ \\ Maria Carolina de Andrade Freitas ${ }^{7}$
}

\begin{abstract}
Resumo:
A medicalização da vida constitui um discurso e um processo presente em diversos contextos, inclusive nas instituições educacionais, alcançando crianças e adolescentes em idade escolar. Percebe-se, nesse movimento, uma redução da compreensão de temas como saúde, aprendizagem, educação, cuidado e assistência a uma afirmação biomédica que negligencia os aspectos sociais em prol de uma leitura biologizante. Dessa forma, o discurso e as práticas medicalizantes podem atribuir às formas de existência múltiplas uma perspectiva reducionista. Este trabalho pretende discutir como a medicalização se insere como prática reducionista que pretende supostamente a inclusão do aluno público-alvo da educação especial na educação brasileira, mas pode produzir efeitos paradoxais e perversos. Para tanto, utilizou-se da revisão narrativa de literatura, em artigos e demais obras que versam sobre o assunto, para descrever e discutir a problemática apresentada. Importa apontar, contudo, a construção de uma educação que compreenda o aluno como sujeito singular, indo além de uma perspectiva classificatória fundamentada em uma lógica biomédica. Busca-se valorizar e reconhecer as diversas formas de ser e aprender, considerando na análise fatores sociais, políticos e culturais como fundamentais na discussão acerca da educação inclusiva.
\end{abstract}

\footnotetext{
1 Discente do 5o período da Universidade do Estado de Minas Gerais. E-mail: iiasmimss@gmail.com. ORCID iD: http://orcid. org/0000-0003-4378-9411.

2 Psicóloga graduada pela Universidade do Estado de Minas Gerais. E-mail: helenacaversan@gmail.com. ORCID iD: http:// orcid.org/0000-0002-4192-4184.

3 Discente do 7ํㅜ período da Universidade do Estado de Minas Gerais. E-mail: kellybio@gmail.com. ORCID iD: http://orcid. org/0000-0001-8293-5421.

4 Discente do 10 período da Universidade do Estado de Minas Gerais. E-mail: miguelevol@gmail.com. ORCID iD: http://orcid. org/0000-0003-3339-2779.

5 Discente do 70 período da Universidade do Estado de Minas Gerais. E-mail: thauanyddiniz@yahoo.com. ORCID iD: http:// orcid.org/0000-0002-7114-6782.

6 Discente do 70 período da Universidade do Estado de Minas Gerais. E-mail: renatagm1@hotmail.com. ORCID iD: http:// orcid.org/0000-0002-4908-4917.

7 Doutora em Educação pela UFES - ES. Docente do curso de Psicologia na Universidade do Estado de Minas Gerais. E-mail: maria.freitas@uemg.br. ORCID iD: https://orcid.org/0000-0002-6585-1370.
} 
Palavras-chave:

Educação. Medicalização. Inclusão.

\title{
Labyrinths of inclusion: medicalization as a perverse practice in education
}

\begin{abstract}
:
The medicalization of life is a process and discourse adopted in several contexts, including educational institutions, reaching school-age children and adolescents. In this movement, there is a reduction in the understanding of themes such as health, learning, education, care and assistance to a biomedical statement that neglects the social aspects in favor of a biologizing reading. Thus, the medicalizing discourse and practices can attribute a reductionist perspective to multiple forms of existence. This work intends to discuss how medicalization is inserted as a reductionist practice that supposedly intends to include the target public student of special education in Brazilian education. Therefore, a narrative literature review was used, in articles and other works that deal with the subject, to describe and discuss the problem presented. It is important to indicate, however, the construction of an education that understands the student as a singular subject, going beyond a classificatory perspective based on a biomedical logic. It is intended to value and recognize the different ways of being and learning, considering in the analysis social, political and cultural factors as fundamental in the discussion about inclusive education.
\end{abstract}

Keywords:

Education. Medicalization. Inclusion.

\section{Laberintos de inclusión: la medicalización como práctica perversa en la educación}

Resumen:

La medicalización de la vida es un discurso y un proceso presente en diversos contextos, incluyendo las instituciones educativas, llegando a escolares y adolescentes. Barnacle, en este movimiento, redujo la comprensión de temas como salud, aprendizaje, educación, cuidado y asistencia a un enunciado biomédico que descuida los aspectos sociales en la proliferación de una conferencia biologizante. De esta forma, o discurso sobre las prácticas medicalizadoras, se pueden atribuir múltiples formas de existencia a una perspectiva reduccionista. El propósito de este artículo es discutir cómo la medicalización se inserta en una práctica reduccionista que, supuestamente, pretende incluir al público objetivo de la educación especial en la educación brasileña. Por tanto, se utiliza una revisión de la literatura narrativa, basada en otros trabajos que abordan el tema, para descreer y discutir el problema presentado. Es importante apostar, sin embargo, por la construcción de una educación que comprenda o sola en un sujeto singular, yendo más allá de una perspectiva clasificatoria basada en una lógica biomédica. Busca valorar y reconocer las diferentes formas de ser y aprender, considerando el análisis de factores sociales, políticos y culturales que son fundamentales para la discusión sobre educación inclusiva.

Palabras clave:

Educación. Medicalización. Inclusión. 


\section{Introdução}

Giorgio Agamben (2009) é certeiro em alertar acerca da posição do homem contemporâneo como aquele capaz de afastar-se de seu tempo e, justamente por isso, capaz de enxergar as luzes e as sombras características de sua época. O filósofo italiano profere que

Pertence verdadeiramente a seu tempo, é verdadeiramente contemporâneo, aquele que não coincide perfeitamente com este, nem está adequado às suas pretensões e é, portanto, nesse sentido, inatual; mas, exatamente por isso, exatamente através desse deslocamento e desse anacronismo, ele é capaz, mais do que os outros, de perceber e apreender o seu tempo (AGAMBEN, 2009, p. 58-59).

Partindo dessa lógica, a Psicologia como prática que se propõe a escutar as mazelas de sua época, vincula-se à contemporaneidade de Agamben e, desse modo, debruça-se nos estudos, análises e observações dos fenômenos que acometem a sociedade contemporânea. Um desses fenômenos, presente e crescente no Brasil, intitula-se "medicalização da vida" e, de acordo com o Ministério da Saúde (BRASIL, 2019), acomete em sua maioria sujeitos vinculados a lógicas institucionais, como adultos em privação de liberdade, usuários de serviços de atenção à saúde mental e crianças e adolescentes em idade escolar. A instituição escolar, desse modo, figura como um dos locais possíveis para que ocorra a medicalização da vida, visto que concentra grande número de crianças e adolescentes.

Nesse ínterim, a "medicalização" refere-se a uma substituição da complexidade que é inerente à vida humana para a afirmação de concepções deterministas que desconsideram os elementos sociais envolvidos na fabricação das classificações. De forma que as questões das subjetivações são reduzidas a leituras puramente orgânicas ou a leituras estigmatizantes e naturalizadas dos aspectos sociais (BRASIL, 2019). A própria organização em sociedade implica, de acordo com Freud (1930[1929]/1996), um certo sentimento de mal-estar que é constitutivo ao sujeito. Isso significa, de modo mais amplo, que a busca por um funcionamento perfeito e sem falhas tampouco é possível, embora o que se observa seja justamente um movimento nessa direção: tamponar o que quer que se apresente como falta, e suprimir o que quer que se manifeste como excesso, a fim de conceder às características subjetivas, nomeações normativas.

A constituição do sujeito circula por ambientes sociais e comuns, porém, há também uma parcela bastante particular, que deriva das experiências de cada um, isto é, tem seu percurso pela vivência íntima, pela maneira com que cada um enfrenta o impossível da realidade, apresenta-se no mundo e simboliza a sua própria existência. O sujeito, assim, tem a sua constituição não apenas pautada na matéria biológica, mas também nas exigências narcísicas, familiares e culturais. Diante disso, Dunker (2015) reconhece que existe um esforço por parte da indústria farmacêutica, de um lado, e da psiquiatria médica, de outro, em "nomear normativamente" - por meio das categorias diagnósticas - e em "solucionar" - mediante a intervenções medicamentosas - as faltas e falhas constitutivas dos sujeitos. Essa tentativa acaba sobrepondo as apresentações singulares, recorrendo à insistente nomeação do mal-estar a partir da exploração do sofrimento a um ponto além do sintoma, trabalhando em vias a globalizar as formas de sofrer e as respostas possíveis a esse sofrimento.

No que tange ao aluno público-alvo da educação especial, ele emerge nesse cenário como uma expressão de que as exigências impostas pela sociedade não funcionam. A sociedade e as instituições não gostam de ser lembradas de que elas falham. Como Freud (1930[1929]/1996) nos aponta, tenta-se de todas as formas escapar dessa lembrança, mas o que o aluno público-alvo da educação especial faz com relação a isso é justamente evidenciar essa falha. Ele mostra que o funcionamento dentro de algumas determinantes específicas não é para todos, pois existem aqueles que não se encaixam, por diversos motivos. No caso da educação, o aluno público-alvo 
da educação especial relembra a instituição escolar de suas próprias falhas. Na tentativa de apagar essa lembrança, o que aparece é a ânsia em excluí-los ou adaptá-los. Nesse sentido, é preciso cuidar para que professores, psicólogos e demais profissionais da educação não se tornem instrumentos de uma prática de inclusão perversa, ${ }^{8}$ e sim promovam práticas inclusivas efetivas.

Com efeito, o psicólogo que se insere nas instituições escolares deve se propor a colocar-se além, tal qual apresenta Agamben (2009), a fim de compreender os aspectos envolvidos no fenômeno crescente da medicalização nas escolas e, desse modo, ser capaz de atuar e intervir buscando a sustentação do espaço, da voz e dos direitos desses sujeitos, bem como concorrer para que os demais envolvidos nesse circuito, sejam eles educadores, médicos ou a própria família, problematizem suas práticas e concepções. Sendo assim, a partir das questões levantadas, este artigo se organiza com o objetivo de apresentar de que forma a medicalização se insere como "prática perversa" de inclusão do aluno com diferente especificidade na educação brasileira. Para tal, utilizou-se de uma revisão narrativa de literatura, pautada em artigos científicos de autores como: Sawaia (2001), Ribeiro et al. (2020), Guarido (2007), Angelucci (2014), Meira (2012), Moysés e Collares (2010), Bassani (2017), entre outros, além da contribuição de Michel Foucault sobre a produção dos anormais e sua discussão sobre o poder disciplinar e a medicalização da vida, com intuito de descrever e discutir os materiais disponíveis sobre o tema, além de propor um debate que contribua para o desenvolvimento teórico do tópico em questão.

Trazer à tona a inclusão em contexto educacional em contraposição à medicalização e à patologização parece-nos importante, em vista de que não se trata de um movimento novo. No entanto, quando lido a partir do contexto brasileiro, encontram-se pontos de avanços e retrocessos: um dos principais avanços foi a implantação, em 2008, da Política Nacional da Educação Especial (PNEE), que modificou as perspectivas educacionais a partir da ideia de uma educação inclusiva. Assim, "a organização de escolas e classes especiais passa a ser repensada, implicando uma mudança estrutural e cultural da escola para que todos os alunos tenham suas especificidades atendidas" (BRASIL, 2008, p. 5). No entanto, após as eleições presidenciais de 2018, houve uma tentativa, por parte do governo federal, de alterar, no ano de 2020, as políticas relacionadas à inclusão e, dessa forma, um problema que já era de comum preocupação, tornou-se ainda mais grave. Felizmente, esse documento não foi aprovado pelo Plenário do Supremo Tribunal Federal (STF), e a PNEE de 2008 segue ainda em vigor. Contudo, cabe ressaltar, como sugerem Iácono e Parada (2020) que há uma constante ameaça a toda história e luta pela educação inclusiva no cenário vigente. $\mathrm{Na}$ PNEE que fora proposta pelo governo federal em 2020, há o retorno ao pensamento de um ensino excludente, que segrega os alunos público-alvo da educação especial, caminhando na contramão de todas as lutas travadas até agora (BRASIL, 2020). A inclusão é um instrumento incontestável de emancipação e superação da discriminação (IÁCONO; PARADA, 2020), sem dúvidas. Porém, a discussão proposta neste artigo ressalta que é preciso não deixar para trás a reflexão acerca do que a educação inclusiva significa e sobre como ela se aplica, para que não seja utilizada como instrumento de exclusão velada, como destaca Sawaia (2001) na discussão sobre as artimanhas da exclusão e conforme se evidencia na tentativa das novas políticas governamentais.

8 Conforme nos apresenta Bader Sawaia (2001) em sua obra As artimanhas da exclusão: Análise psicossocial e ética da desigualdade social, a inclusão perversa se configura como uma prática dissimuladora que se apoia na ideia de inclusão sem que de fato produza as condições e mudanças estruturais necessárias que possibilitem a inserção dos sujeitos, públicos-alvo das políticas de educação especial de acordo com a perspectiva da inclusão, na educação. Retornaremos a essa discussão mais adiante. 


\section{A medicalização e a patologização do aluno}

A inauguração da ciência moderna, no século XVII, evidencia uma importante mudança epistemológica, em consonância com a qual há o nascimento da medicina e, posteriormente, da psiquiatria que, por sua vez, passa considerar o sofrimento mental a partir de uma lógica de categorização, de forma a agrupar manifestações patológicas semelhantes em compartimentos de quadros clínicos e diagnósticos (RIBEIRO et al., 2020).

No seio dessa classificação criteriosa, testemunha-se, em 1952, o surgimento do Manual Diagnóstico e Estatístico dos Transtornos Mentais (DSM), que atualmente encontra-se em sua quinta edição. Ribeiro et al. (2020) aponta que se pode considerar a publicação do DSM como um marco na história da psiquiatria, já que, a partir dele, as classificações psiquiátricas ganham proporções jamais atingidas "[...] ao deixarem de ser ferramentas de auxílio clínico para se tornarem uma forma de intervenção hegemônica" (RIBEIRO et al., 2020, p. 47). De acordo com os autores, durante os anos de atualização do Manual, foi possível observar que, ao longo das atualizações nas edições, o que aconteceu foi um aumento alarmante no número de categorias diagnósticas, ou seja, no número de nomeações disponíveis para os sofrimentos subjetivos.

O DSM-I, publicado em 1952, possuía 106 categorias psicopatológicas, baseando suas compreensões em perspectivas psicanalíticas. No DSM-II, publicado em 1968, esse número já subiu para 182 e a noção de psicopatologia começou a ser melhor embasada em uma perspectiva comportamental, mostrando o início da divergência entre psiquiatras norte-americanos e psiquiatras europeus. Essa divergência culminou na terceira edição do Manual, publicada em 1980, na qual as categorias diagnósticas saltaram para 265, na primeira edição, e 292 na segunda. Em 1994, o DSM ganha sua quarta edição, que contava com 297 categorias ao longo de suas 886 páginas. É nesse momento, com o apagamento total da etiologia da doença em detrimento de um modelo nosográfico, que o Manual passa a figurar como um método exato de diagnóstico psiquiátrico a partir do cumprimento de um "checklist" (RIBEIRO et al., 2020). E, em 2013, é lançada a atual edição do DSM, o DSM-V, com 947 páginas e mais de trezentas categorias.

Observa-se, a partir da evolução do DSM e da própria psiquiatria, que a questão classificatória tomou o lugar central nessa discussão, impacto este que não se restringiu ao âmbito clínico, atingindo também as esferas sociais. A medicina passou a nomear e classificar fenômenos condizentes ao mal-estar e a questões que fogem às normas sociais, delimitando inclusive os seus destinos: os rótulos diagnósticos e o aumento excessivo do uso de psicofármacos merecem destaque e atenção. Não se trata de afirmar a não existência de determinadas classificações e seus correspondentes. Mas de destacar o aumento expressivo dos diagnósticos e suas indicações de tratamento que, grande parte das vezes, tornam-se medicalizadoras das existências, reduzindo ao modelo biomédico importantes questões sociais. Os efeitos instrumentalistas das classificações desconsideram as múltiplas possibilidades de expressão dos sujeitos diagnosticados em seus contextos relacionais e sociais.

Dentro das escolas observa-se cada vez mais professores e funcionários da educação encaminhando crianças e adolescentes a psiquiatras, já com pré-diagnósticos recolhidos em sala de aula (GUARIDO; VOLTOLINI, 2009, p. 240), ou, quando se trata de crianças já diagnosticadas, é “[...] comum também que agentes das equipes escolares insistam em perguntar aos pais, quando se encontram diante de alguma manifestação não conhecida (ou não desejada) de uma criança que está em tratamento, se ela foi corretamente medicada naquele dia”. É possível entender, juntamente com Beltrame et al. (2019, p. 3), que existe uma lógica pautada em buscar soluções para problemas escolares a partir de esferas não escolares, principalmente no que tange a especulações organicistas "[...] que tentam localizar no indivíduo a causa da não aprendizagem, reproduzindo formas de exclusão e silenciamentos, negligenciando a complexidade intrínseca aos processos de escolarização [...]" e às peculiaridades e necessidades de cada sujeito. 
Esse costume de pré-diagnósticos só aponta um problema: o de que, ainda assim, os alunos público-alvo da educação especial carregam uma espécie de estigma de um suposto estado patológico, constante e estático (ANGELUCCI, 2014). Essa não é uma lógica inclusiva, muito pelo contrário, é uma prática segmentária que remete a tempos passados, nos quais os alunos eram divididos entre escolarizáveis e não escolarizáveis, deixando a criança submetida ao universo médico-pedagógico (GUARIDO, 2007). Isso é problemático, porque a maneira que se inclui o aluno é, essa sim, deficitária. Não há a reflexão acerca de um processo educativo que valorize de fato as diferenças, processo este muito mais interessante do que uma educação que se propõe a formatar e encaixar os alunos a determinada lógica.

Nesse ponto, a inserção da visão médica nesse contexto mantém as diferentes necessidades como expressão de anormalidade, algo que precisa ser curado e encaixotado (ANGELUCCI, 2014).

Como aponta Meira (2012), muitos profissionais da educação atribuem exclusivamente às características biológicas do aluno a sua dificuldade em aprender. De acordo com Guarido (2007, p. 160): “[...] a medicalização em larga escala das crianças nos tempos atuais pode ser lida também com apelo ao silêncio dos conflitos, negando-os como inerentes à subjetividade e ao encontro humano." A medicalização e a patologização se apresentam como um recurso para eximir a responsabilidade e esconder uma realidade: a de que o sistema educacional, nesse formato, não é eficiente para criança alguma.

A patologização do aluno recorta seu corpo de um contexto maior, ela estabelece um controle sobre o corpo do aluno. E quando a tentativa de inclusão é feita por meio da patologização e seu controle apenas, acaba-se diante de um processo que não corrobora para a perspectiva de uma inclusão de fato, pois, se as particularidades do aluno são ignoradas, não se estabelece a vontade de aprender, muito pelo contrário, não se aprende, se prende. É preciso que seja conhecido não apenas o diagnóstico de um aluno, quando isso é necessário, mas também seu nome e sua história, invertendo a lógica dita produtiva, que não se preocupa com as diferenças, mas é obcecada com os diferentes, com seu fetiche de enquadrá-los (ANGELUCCI, 2014).

Trata-se, então, de repensar a maneira como o aluno é incluído e a maneira como são enxergados. Partindo de uma lógica produtivista e nefasta, caminha-se para um ponto no qual não se avista um aluno, mas sim uma peça defeituosa de um sistema que precisa rodar, a custo de óleo e sangue. Ao observar um "sujeito", é preciso saber seu nome, sua história e seus anseios, para que um processo educativo se efetive de fato, fazendo não somente um movimento de envolvê-lo, porém também de deixar ser envolvido por ele.

A lógica medicalizante e patologizadora transforma o aluno em um diagnóstico, trata dele como se fosse uma parte defeituosa, alguém em quem falta uma peça, não é completo e, por isso mesmo, precisa ser adaptado. Porém, essa visão trabalha em um sentido oposto ao que seria favorável para o aluno, porque é a visão da inclusão concreta do aluno que permite que ele melhor empreenda a jornada que é a educação. Toda existência, de que modo quer que se apresente, é legítima.

\section{O controle do sujeito através da medicalização}

A medicalização, como explicitado anteriormente, é utilizada sob um aspecto negativo, referindo-se tanto ao excesso de medicamento prescrito quanto à multiplicação de intervenções médicas em áreas que não se vinculam à medicina. Dessa forma, a medicina passou a determinar regras de conduta e de moral, regulamentando comportamentos e convertendo outras áreas do saber à sua dependência. A essa instância, Foucault (2010) dá o nome de "Biopoder", ou seja, a incorporação de diversas instituições ao poder da medicina construindo uma nova normativa social.

A disciplina tenta reger a multiplicidade dos homens na medida em que essa multiplicidade pode e deve se transformar em corpos individuais que devem ser vigiados, treinados, utilizados e 
eventualmente punidos. Em decorrência disso, a nova tecnologia que se instala dirige-se à multiplicidade dos homens, não na medida em que eles se resumem em corpos, mas na medida em que ela forma uma massa global, afetada por processos de conjunto que são próprios da vida, como o nascimento, a morte, a produção, a doença, etc. (FOUCAULT, 2010, p. 204).

O sistema capitalista impulsionou e fortaleceu o poder da medicina na sociedade. Devido ao desejo hegemônico do crescimento econômico, os corpos foram direcionados ao trabalho como força primordial da produção, dessa forma criou-se a percepção de controle dos sujeitos por meio de seus corpos (FOUCAULT, 2011). A união da medicina com as demais áreas da saúde e da política, potencializou novas maneiras de governo dos corpos individuais e coletivos, gerenciando modos de existir, minimizando doenças e promovendo saúde (ROSE, 2007).

A sociedade capitalista, sob o poder do saber médico, passou a se orientar diante do que é normal e anormal (FOUCAULT, 2010), atribuindo inestimável valor a um sistema de normalidade. Os sujeitos dominados por esse controle, moviam-se conforme as regras médico-sanitárias que determinavam as formas de prevenção das doenças. Dificuldades sociais, momentos turbulentos da vida, diferenças culturais, entre outros modos de ser que não cabiam no sistema de produção e na normalidade, foram tratados como fatores anormais, doenças que necessitavam de medicamentos, de modo a conduzir os corpos anormais para o sistema da normalidade.

De acordo com Barros (2010, p. 89), os medicamentos começaram a ser utilizados de maneiras além de suas prescrições para o alívio de sintomas e para cura de doenças, entrando em uma esfera na qual o ideário ao redor dos medicamentos era o de "pílulas mágicas", as quais solucionariam todos os problemas. Na escola, os medicamentos e saberes da saúde ganham força como dispositivos de controle e classificação, potencializando condutas esperadas no sistema de normalidade. Há um comportamento pré-determinado para uma infância 'normal', em que as crianças são seres concentrados, calmos, disciplinados, dóceis, educados, inteligentes e obedientes. Para Moysés e Collares (2010) esse padrão é uma utopia que permite a condução de todos os comportamentos diferentes ao estipulado como possíveis transtornos. Os laudos médicos oferecem rótulos às crianças que, muitas vezes, possuem condições plenas de aprendizado, mas são consideradas fora da normalidade e passam a acreditar que, por terem um problema, não conseguirão aprender (BASSANI, 2017). Dessa forma,

A partir da estigmatização, as pessoas assim marcadas passam a receber um tratamento diferente do que é dirigido aos normais, como se isso fosse absolutamente natural. Uma diferença em relação ao padrão, diferenças, já acordadas como negativas, transformam totalmente as relações, como se realmente permitissem prever/identificar pessoas ritualmente poluídas (MOYSES, 2001, p. 249).

A associação entre a medicina e a farmacologia no ambiente escolar foi incumbida de controlar as ocorrências do fracasso escolar, medicando crianças diferentes do padrão utópico do que é normal. Por consequência, esses alunos que, por suposição, não são capazes de aprender, são considerados portadores de transtornos incapacitantes e, dessa forma, só obteriam conhecimentos se fossem medicados. Garrido e Moysés (2011) afirmam que o processo de medicalização de crianças é uma forma de violência, visto que se espera que todas as crianças, independentemente de suas competências, desenvolvam um desempenho no padrão esperado. A partir de alguns estudos em escolas públicas brasileiras, verificou-se que

Os alunos começam a ser encaminhados para profissionais de saúde e, muitas vezes, são medicados cada vez mais cedo. Sendo assim, passam, com base nos laudos médicos, a fazer parte da estatística da Educação Especial, apesar de a Política Nacional de Educação Especial na Perspectiva da Educação Inclusiva (2008) definir que o seu público-alvo é composto de 
alunos com deficiência, com transtornos globais do desenvolvimento e altas habilidades/ superdotação (BASSANI, 2017, p. 179).

Ao fazer parte do processo de construção da Declaração de Salamanca, a pauta acerca da discussão e implantação de direitos educacionais reservados aos alunos público-alvo da educação especial, se tornou uma realidade no Brasil (BRASIL, 1997). Segundo Angelucci (2014, p. 122), houve um importante progresso advindo dessa Declaração para as políticas educacionais brasileiras quando se defendeu uma escolarização praticada em conjunto, sendo necessária a "reestruturação do sistema educacional e dos processos educativos", além de propor "[...] a definição da população com necessidades educacionais especiais como aqueles(as) educandos(as) que vivem, ainda que temporariamente, dificuldades em seu processo de ensino-aprendizagem". Contudo, as reformulações posteriores na legislação do país para oferecer suporte às mudanças reforçaram um estigma médico excludente diante da caracterização do aluno público-alvo da educação especial (MARQUEZAN, 2008).

A sobreposição do saber médico sobre o saber educacional retira a potência dos educadores, desapropriando o professor de sua própria prática (MOYSÉS; COLLARES, 2013). Subentende-se cada vez mais que educadores e demais trabalhadores da educação necessitam ter conhecimento sobre teoria, conceitos e diagnósticos, como competência primordial diante do trabalho com o aluno público-alvo da educação especial, visando a uma abordagem multidisciplinar. Nesse sentido,

Não à toa, cotidianamente deparamo-nos com educadores(as) que se dizem incapazes de trabalhar com essa população especial. São educadores(as) que têm sido alijados(as) de seus saberes, em nome de uma necessidade de conhecimentos de um determinado extrato do campo da Saúde, sem os quais não seria possível escolarizar a parcela - cada vez maior - de educandos(as) com algum diagnóstico. São profissionais com estudo e experiência, mas cuja especificidade, que é a formação em Educação, tem sido dispensada, em nome de uma formação paramédica (ANGELUCCI, 2014, p. 124, grifos do autor).

A educação efetivamente inclusiva possui uma concepção de reconhecimento sobre as diversas formas de ser e de aprender que coexistem, fato esse que carece da mesma diversidade no formato de ensino e de relacionamento com o outro. Pode-se inferir que, baseado nessas primícias, a própria educação é um processo inclusivo, visto que cada aluno, com sua história e cultura particulares respeitadas, conseguem aprender juntos (MEC, 2008). A inclusão dos alunos público-alvo da educação especial, medicalizados ou não, perpassa pelo reconhecimento de um aprendizado cujo objetivo é um modo de construção de mundo no qual todos são capazes de aprender.

\section{O "aluno especial" e a perspectiva de uma "falta" como "falha"}

No século XIX, com o aumento da visão mecanicista, caracterizada pelo modelo biomédico, observou-se uma grande carga colocada sobre o corpo, visto que o humano era julgado a partir de sua validez, ou seja, o corpo tinha que funcionar como uma máquina e, assim, não poderia haver imperfeições (RESENDE, 2016). Essa visão de corpo-máquina pode ser encontrada desde os pensamentos de Descartes (1637/1996) acerca do dualismo mente e corpo, que tenta garantir ao ser humano o seu privilégio metafísico. Essa separação possibilitou uma divisão mais categórica entre cada uma dessas partes, na medida em que a mente era verificada a partir de áreas da filosofia e da religião, e o corpo como sendo responsabilidade da medicina (CASTRO; ANDRADE; MULLER, 2021). 
Dessa forma, essa lógica utiliza de classificações para organizar a sociedade em: indivíduos úteis e normais e/ou os ditos "anormais" - dado que possuem déficit em determinado ponto biológico -, e, assim, asseguram um certo controle sobre a comunidade, na tentativa de manter tudo e todos nesse estado e, ainda, obter um resultado considerado perfeito. De fato, essa questão pode ser relacionada aos aspectos que concernem aos cidadãos em idade escolar, na medida em que as pessoas e instituições de maior poder social conseguem assegurar um certo controle sobre a "perfeição" da sociedade futura.

Essa tentativa da modernidade de colocar tudo e todos em uma ordem perfeita, faz com que se crie um mal-estar na sociedade diante das diferenças que se instalam. Contudo, Foucault (1990) afirma, a partir de um conto de Jorge Luís Borges, que as pessoas não conseguem ter sucesso nas tentativas exageradas de determinar certas classificações do universo, de forma que "[...] classificações não são espelhos da realidade, mas construções, arranjos que configuram um domínio da realidade sistematizando sua multiplicidade de maneira inteligível [...]" (JUNIOR, 2014, p. 13). Em vista disso, os ditos "anormais", que são vistos como incompletos, saem dessa ordem que tenta suavizar as diferenças e, assim, partem para a tentativa de corrigir a desordem (ZORZANELLI; ORTEGA; BEZERRA JÚNIOR, 2021). Seguindo essa trilha,

O filósofo da ciência Ian Hacking (HACKING, 2006) diz que nosso mundo é um mundo de classificações e que essas classificações, ou nomes, têm efeitos particulares quando se referem a comportamentos de pessoas. Escreve também que, por trás de cada classificação, existe uma estrutura que engloba cinco aspectos primários: a classificação, os indivíduos, as instituições, o conhecimento e os especialistas (BRZOZOWSKI; CAPONI, 2009, p. 1166).

Percebe-se, com isso, a ignorância, total ou parcial, frente à dimensão de sujeito da criança que apresenta alguma deficiência, visto que, na maioria dos casos, a "falta de algo" - estabelecida pela deficiência - é preenchida com medicamentos, no intuito de encaixar o indivíduo na norma pretendida pelo sistema educacional. No entanto, a Organização Mundial da Saúde (OMS) entende que "[...] saúde é um estado de completo bem-estar físico, mental e social [...]" (OMS/WHO, 1946, p. 1), o que contraria o senso comum e as diretrizes antigas, as quais consideram a saúde como apenas a ausência de enfermidade. Essa visão formalizada, portanto, evidencia que o sujeito não pode ser limitado apenas às questões biológicas.

Entretanto, o sistema educacional gera constantemente empecilhos, e considera certos estudantes como problemas, ou seja, como seres que precisam ser "controlados" de alguma forma (SOUZA, 2009). Logo, com o intuito de controlá-los, encaixam-se os sujeitos e os limitam a quadros de disfunção neurológica, transtornos, ou falhas de processamento cognitivo e, consequentemente, erigem-se métodos para adaptá-los: especialmente utilizando medicamentos. Em vista disso, a criança é estigmatizada pelos inúmeros transtornos alocados pelo viés organicista. É interessante destacar que essa lógica medicalizante se torna um método punitivo, pois os remédios podem ser denominados de "drogas da obediência". No entanto, ao apresentar um diagnóstico, a criança é estigmatizada como um sujeito disfuncional, gerando a remediação de um tratamento especializado - e, assim, o entendimento pacífico dos adultos -, ou a justificativa de todos os seus comportamentos em função do seu laudo médico. Dessa forma, a sociedade coloca as atitudes indesejáveis como algo já esperado (SOUZA, 2009) e, como afirma Foucault (2001, p. 73), o que passa a caracterizar o

[...] indivíduo a ser corrigido, portanto, é que ele é incorrigível. E, no entanto, paradoxalmente, o incorrigível, na medida em que é incorrigível, requer um certo número de intervenções específicas em torno de si, de sobreintervenções em relação às técnicas familiares e corriqueiras de educação e correção, isto é, uma nova tecnologia da reeducação, da sobrecorreção. De modo que vocês vêem desenhar-se em torno desse indivíduo a ser corrigido a espécie de jogo entre 
a incorrigibilidade e a corrigibilidade. Esboça-se um eixo da corrigível incorrigibilidade, em que vamos encontrar mais tarde, no século XIX, o indivíduo anormal precisamente.

Percebe-se, então, que essa forma de controle, pelo viés da medicalização, é uma maneira de ajustar a criança ao que é aceitável e considerado normal. Foucault (2008) utiliza o termo "panoptismo" para descrever essa questão, visto que os adultos utilizam de mecanismos de poder para modificar os ditos "faltantes", na intenção de modificá-los, domá-los e vigiá-los.

Ao investigar a história e evolução das práticas educacionais voltadas aos alunos público-alvo da educação especial, percebe-se que só recentemente estes começaram a frequentar as escolas regulares, o que se deu a partir da Declaração de Salamanca (UNESCO, 1994). Ademais, o direito a frequentar a escola regular só foi realmente garantido a todos a partir da PNEE de 2008, que, como dito anteriormente, se incumbiu de propor a educação a partir de uma perspectiva inclusiva que atendesse às especificidades de todos os alunos. A criança era separada da sociedade, em uma instituição educacional especial, para que, supostamente, fosse atendida, mas tal pressuposição seguiu uma lógica manicomial e acabou por excluir a diversidade, a partir do momento em que todas as diferenças foram reunidas em um mesmo local, afastado e excluído da sociedade geral. Em 1961, por exemplo, o número de instituições desse tipo ampliou, isentando ainda mais o dever governamental em promover políticas inclusivas (FERREIRA, 1998).

Somente com os novos direitos adquiridos essas crianças passaram a frequentar as escolas regulares, na tentativa de igualar o direito à educação para todos os indivíduos. Entretanto, os estudantes com "condutas disfuncionais" são compreendidos sob a insígnia da falta e da falha, o que corrobora para que o sistema educacional proponha correções amparadas nos dispositivos biomédicos, tentando preencher aquilo que se julga faltar. (SOUZA, 2009).

Posto isso, a ideia ligada ao molde biomédico também interfere na forma como são constituídas as políticas públicas, visto que focam majoritariamente na reparação do corpo, para que se encaixe nas categorias sociais impostas, ao invés de verificar e modificar a forma como o contexto social se apresenta. Logo, é preciso romper com essa noção de anormalidades e observar as crianças público-alvo da educação especial como parte da diversidade humana. Diante disso, esses fatores deveriam ser considerados como marca social, ou seja, não os restringir apenas ao âmbito médico, mas ampliar os olhares de outros setores acerca desse fenômeno, para que se indague o que quer que se apresente como falta, a partir de uma perspectiva para além do corpo.

\section{Práticas e inversões: processos de inclusão perversos como uma redução da análise das diferenças}

A partir do momento em que a compreensão existencial do sujeito e de seu corpo são capturadas puramente pelo discurso biomédico, sob uma ótica de promoção de saúde baseada na lógica medicalizante e patologizante, criam-se categorias como normal/patológico, saudável/ patológico, "oposições conceituais redutoras na análise das diferenças" (BAUDRILLARD, 1995, p. 31 apud SAWAIA, 2001, p. 107). O processo de dominação e controle se instaura, pois "as oposições paradigmáticas não são apenas instrumentos de uma análise semiológica do mundo dos objetos, mas discriminadamente sociais, traços não só formalmente distintos, mas socialmente distintivos" (BAUDRILLARD, 1995, p. 31 apud SAWAIA, 2001, p.107).

\footnotetext{
9 "O panóptico pode ser descrito como uma estrutura física, um prédio circular com uma torre central, de onde se pode observar as celas construídas à sua volta [...] Logo, quem vê nunca é visto, assim como quem é visto nunca vê e está hipoteticamente sob constante observação" (SPÍNDOLA, 2011, p. 2).
} 
Dessa forma, a adoção da perspectiva puramente biomédica no campo da educação, se sobrepondo imperativamente aos saberes do campo pedagógico e educacional, pode potencializar práticas excludentes ou, como situa Bader Sawaia (2001), um processo de "inclusão perversa". A autora (SAWAIA, 2001) aponta que a sociedade exclui para incluir, de forma que inclusão e exclusão se tornam um par indissociável, em uma relação dialética. Tal situação é percebida de forma que grupos historicamente segregados ocupam o espaço social, mas estão incluídos de forma perversa, uma vez que a marginalização permanece no imaginário sociocultural, e o estigma também se conserva. Para Goffman (1963) "estigma" consiste em determinada característica ou atributo que torna o sujeito diferente, fazendo com que ele seja alojado em uma categoria de descrédito, impedindo sua inserção social de forma efetiva. Assim, configura-se uma dialética, pois parte-se do princípio de que se existe um ideal e uma demanda de inclusão é porque decorre de um processo de exclusão.

Ademais, Bader Sawaia (2001) nos introduz o importante conceito de "sofrimento ético-político" para se refletir acerca da dialética exclusão/inclusão, sendo uma possibilidade de pensar de forma contrária à lógica puramente biomédica, que localiza no indivíduo as origens de seu sofrimento, desconsiderando fatores sociais, econômicos e culturais. Utiliza-se de uma perspectiva ético-política, pois entende-se que o indivíduo sofre, entretanto, por não se encaixar na ordem social pré-estabelecida, esse sofrimento não tem seu ponto de origem no próprio indivíduo, mas sim na estrutura social que não foi delineada e construída para incluí-lo.

Processos de inclusão perversos se configuram como formas de disciplinarização dos excluídos, uma tentativa de controle social e manutenção do ideal vigente. O ideal de inclusão só pode se concretizar a partir de uma mudança estrutural que permita a inserção efetiva do indivíduo. É preciso que se problematize a lógica medicalizante, a fim de evitar que esta permeie e inverta a prática de inclusão, pois, uma vez que se faz possível a ocorrência de medidas como essas, passa-se a compreender que todos partem do mesmo ponto, afinal, estariam todos incluídos, endossando um discurso meritocrático que desconsidera as vulnerabilidades e obstáculos experimentados por grupos histórica e socialmente excluídos.

É possível observar tal lógica perversa operando no âmbito educacional quando há a ocorrência de diagnósticos massivos, que resultam em um processo medicalizante, supostamente utilizados como ferramentas para a inclusão. Uma vez que o aluno não atende às expectativas do corpo social, ele passa a ser encaminhado a um tratamento biomédico na tentativa de que ele se assemelhe aos demais e consiga apresentar um "comportamento esperado". Tal operação reduz os problemas de aprendizagem, de ordem educacional, social, econômica, política, e cultural ao campo biomédico. É preciso que se questione o motivo das diferenças funcionais serem lidas única e puramente de forma semiológica, para que haja a garantia do direito à educação aos sujeitos anteriormente excluídos. Garantias de direito, como saúde e educação, não devem perpassar primordialmente por uma leitura reducionista e biologizante.

O que se observa é uma despolitização do sofrimento do excluído, que se configura na redução das causas e origens que geram uma não adequação do sujeito, localizando no corpo biológico o mal-estar, responsabilizando o indivíduo e desconsiderando o cenário no qual ele está instalado, de forma a ignorar a contribuição e os determinantes do processo de saúde/doença, inclusão/exclusão. Reforça-se, assim, um ideal de corpos docilizados (FOUCAULT, 1987), corpos úteis e vantajosos para a estrutura social, produtivos e disciplinados, ativos economicamente, úteis e passivos politicamente, em suma, dóceis. Tendo o objetivo de incluir, emparelhado a um ideal de adaptar, adequar e adestrar, há, portanto, uma inclusão de forma condicional, o que caracterizaria processos de inclusão perversos.

O descrédito social e a redução do sujeito a seu diagnóstico mina o seu potencial de ação. "É o indivíduo que sofre, porém esse sofrimento não tem gênese nele, e sim nas intersubjetividades delineadas socialmente" (SAWAIA, 2001, p. 99). Nesse sentido, observa-se "A perda da confiança 
em si como sujeito potente. Um motivo essencialmente ético, que diz respeito à cidadania, o que qualifica como um sofrimento ético-político" (SAWAIA, 2001, p. 110). Torna-se importante, portanto, compreender tal problemática de um ponto de vista ético-político, a fim de substanciar o potencial de vida e ação dos envolvidos no processo, para que, de fato, sejam incluídos e sua singularidade acolhida.

\section{Conclusão}

Houve uma época em que o conhecimento era, de fato, para poucos. Somente os extremamente ricos e os religiosos dominavam a leitura. Em seu romance O nome da Rosa, Umberto Eco (1989) mostra como o conhecimento era um reduto, um farol em um mundo repleto de mares de ignorância e superstições. A abadia onde se passa a história recebe livros escritos nas mais variadas línguas, dos mais diversos países e autores. O que há ali é um antro de conhecimento tão grande que como o próprio autor relata, atraía os mais diversos monges para ali trabalharem.

Todavia, ao longo do livro percebem-se alguns problemas em relação à biblioteca. $\mathrm{O}$ primeiro: as pessoas não a conhecem. Os monges copistas fazem o requerimento de um livro e o bibliotecário julga se eles podem ter acesso ao conhecimento. Os monges, estudiosos, literatos, fazedores de iluminuras tão belas, encontram-se segregados daquilo que mais buscam: o conhecimento. A lógica da proposição da nova PNEE (BRASIL, 2020), ${ }^{10}$ realizada em 2020, é semelhante às falas do irmão Jorge de Burgos, um velho monge da abadia, que alegava querer o bem de seus irmãos, valorizava o conhecimento e os livros que existiam na biblioteca. Um discurso bonito, um tanto conservador, mas ainda assim bem visto no local. Porém, o irmão Jorge não só impedia que acessassem a biblioteca, como envenenava aqueles que tentavam, mesmo dizendo-se um protetor da abadia, um protetor de seus irmãos. Impedia-os de conhecer "mentiras" escritas ali, naqueles tomos. Evitando que entrassem em contato com o conhecimento dito pecaminoso. A lógica se repete aqui no Brasil, em um discurso que diz visar ao melhor dos alunos e do país, entretanto, na verdade, segrega e envenena aqueles que deveriam ser unidos e protegidos por ele.

A partir do que discutimos, percebe-se a importância do rompimento e da remoção de barreiras que, de forma direta, impedem que se efetive a inclusão. O que nos leva ao segundo problema da biblioteca da abadia. Só era possível acessá-la através de uma passagem secreta e quando lá dentro, o lugar era construído de forma labiríntica. Aqueles que ali entravam se perdiam, eram assustados por artimanhas como ervas alucinógenas, espelhos deformadores e uivos provocados pelo vento. Para acessar o conhecimento, não deve haver entraves, pelo contrário, deve-se buscar incentivos. Não labirintos, mas grandes salões fáceis de acessar, permitindo que todos possam entrar no labirinto que é o conhecer sem que o laudo que a pessoa carrega continue como sinônimo de uma "etiqueta" que segrega e rotula.

A reflexão acerca de quem e de como são os indivíduos sujeitos à inclusão se torna fundamental para avaliar os processos de opressão vivenciados diariamente no contexto escolar e educacional.

O corpo com deficiência somente se delineia quando contrastado com uma representação de o que seria o corpo sem deficiência. Ao contrário do que se imagina, não há como descrever um corpo com deficiência como anormal. A anormalidade é um julgamento estético e, portanto, um valor moral sobre os estilos de vida (DINIZ, 2007, p. 4).

10 A nova PNEE não foi aprovada, mas o fato de ter, em sua proposição, retomado questões já superadas nos aponta que a situação é preocupante. Pois, os retrocessos não cansam de insistir no cenário político atual que empreende uma onda de perdas de direitos e garantias. 
Seguindo ainda o labirinto de Eco, não é possível que apenas se dê acesso a ele. É preciso ensinar a usá-lo, mais, ainda, é preciso que se retire dele as armadilhas. Não adianta fazer como o velho Jorge, ao envenenar as páginas do livro e deixá-lo circular. Pelo contrário, é preciso um trabalho para a remoção das arapucas. É preciso que as armadilhas do labirinto do conhecimento, como a medicalização do sujeito - que, sorrateiramente, desagrega e distancia as individualidades e subjetividades do aluno - sejam retiradas da Torre (a educação). Para permitir, ali, de fato, uma construção ampla e de todos, sem transformar o aluno em um mero copista, sujeitado aos grilhões de ordens que não lhe fazem sentido e só o impedem de alcançar seus direitos e suas conquistas.

\section{Referências}

AGAMBEN, Giorgio. O que é o contemporâneo? e outros ensaios. Chapecó: Argos, 2009.

ANGELUCCI, Carla Biancha. Medicalização das diferenças funcionais - continuísmos nas justificativas de uma educação especial subordinada aos diagnósticos. Nuances: estudos sobre Educação, Presidente Prudente, v. 25, n. 1, p. 116-134, jan./abr. 2014.

BARROS, José Augusto Cabral de. Ampliando espaços para a "medicalização: instrumento para desfrute de melhores níveis de vida? In: CAPONI, Sandra et al. Medicalização da Vida: ética, saúde pública e indústria farmacêutica. Palhoça: Unisul, 2010. p. 89-95.

BASSANI, Elizabete. A colonização médica e a medicalização da educação especial: reflexões sobre laudos na escola. In: VICTOR, Sônia Lopes; VIEIRA, Alexandro Braga; OLIVEIRA, Ivone Martins de (orgs.). Educação Especial Inclusiva: conceituações, medicalização e políticas. Campos dos Goytacazes: Brasil Multicultural, 2017. p. 178-195.

BELTRAME, Rudinei Luiz et al. Diálogos sobre medicalização da infância e educação: uma revisão de literatura. Psicologia em Estudo, v. 24, e. 42566, p. 1-15, 2019.

BEZERRA JUNIOR, Benilton. A psiquiatria contemporânea e seus desafios. In: ZORZANELLI, Rafaela; BEZERRA JUNIOR, Benilton; COSTA, Jurandir Freire (org.). A criação de diagnósticos na psiquiatria contemporânea. 1. ed. Rio de Janeiro: Garamond, 2014.

BRASIL. Ministério da Justiça. Declaração de Salamanca e linha de ação sobre necessidades educativas especiais. Brasília, DF: CORDE, 1994. Disponível em: http://portal.mec.gov.br/seesp/arquivos/pdf/salamanca.pdf. Acesso em: 10 maio. 2021

BRASIL. Ministério da Saúde. Uso de medicamentos e medicalização da vida: recomendações e estratégias. Brasília, DF: Ministério da Saúde, 2019. Disponível em: <http://portalarquivos2.saude.gov.br/images/pdf/2019/fevereiro/14/ ERRATA-Livro-USO-DE-MEDICAMENTOS-E-MEDICALIZACAO-DA-VIDA.pdf> Acesso em: 07 set. 2020.

BRASIL. Declaração de Salamanca e linha de ação sobre necessidades educativas especiais. 2. ed. Brasília, DF: Corde, 1997.

BRASIL. Decreto $n^{\circ}$ 10.502, de 30 de setembro de 2020. Institui a Política Nacional de Educação Especial: Equitativa, Inclusiva e com Aprendizado ao Longo da Vida. Diário Oficial da União, ed. 189, seção 1, p. 6, 01 out. 2020. Disponível em: $<$ https://www.in.gov.br/en/web/dou/-/decreto-n-10.502-de-30-de-setembro-de-2020-280529948\#: :text=DECRETO\%20 N\%C2\%BA\%2010.502\%2C\%20DE\%2030\%20DE\%20SETEMBRO\%20DE,Inclusiva\%20e\%20com\%20Aprendizado\%20 ao\%20Longo\%20da\%20Vida.>. Acesso em: 07 maio 2021.

BRASIL. Decreto 6.949/2009. Promulga a Convenção Internacional dos Direitos das pessoas com Deficiência e seu Protocolo Facultativo, assinados em Nova York, em 30 de março de 2007, 2009. Disponível em: http://www.planalto. gov.br/ccivil_03/_ato2007-2010/2009/decreto/d6949.htm. Acesso em: 02 jan. 2014.

BRASIL. Política Nacional de Educação Especial na Perspectiva da Educação Inclusiva. Brasília, DF: MEC: SEESP, 2008. Disponível em: http://peei.mec.gov.br/arquivos/politica_nacional_educacao_especial.pdf. Acesso em: 16 set. 2013.

BRZOZOWSKI, Fabíola Stolf; CAPONI, Sandra. Transtorno de Déficit de Atenção com Hiperatividade: classificação e classificados. classificação e classificados, 2009.

CASTRO, Maria da Graça de; ANDRADE, Tânia Moraes Ramos; MULLER, Marisa Campio. Conceito mente e corpo através da História. Psicol. estud., Maringá, v. 11, n. 1, p. 39-43, abr. 2006.

DESCARTES, René. Discurso do método. São Paulo: Martins Fontes, 1996. [1637]. 
DINIZ, Débora. O que é deficiência. São Paulo: Editora Brasiliense, 2007.

DUNKER, Christian Ingo Lenz. Mal-estar, sofrimento e sintoma: uma psicopatologia do Brasil entre muros. São Paulo: Boitempo, 2015.

ECO, Umberto. O nome da Rosa. Rio de Janeiro: Editora Record, 1989.

FERREIRA, Júlio Romero A nova LDB e as necessidades educativas especiais. CEDES, v. 19, n. 46, p. 7-15, set. 1998. Disponível em: http://www.scielo.br/scielo.php?script=sci_arttext\&pid=S0101-32621998000300002. Acesso em: 6 maio. 2021

FOUCAULT, Michel. Dits et écrits. Paris: Éditions Gallimard, v. 2, 2001.

FOUCAULT, Michel. Microfísica do Poder. São Paulo: Graal, 2011.

FOUCAULT, Michel. Qu'est-ce que la critique? Bulletin de la Société Française de Philosophie, Paris, v. 84, n. 2, p. 35-63, 1990.

FOUCAULT, Michel. Vigiar e punir: nascimento da prisão. Petrópolis: Vozes, 1987.

FOUCAULT, Michel. Em Defesa da Sociedade: curso no Collège de France (1975-1976). São Paulo: Martins Fontes, 2010.

FREUD, Sigmund. Mal-estar na civilização (1930[1929]). In: FREUD, Sigmund. Edição Standard Brasileira das Obras Psicológicas Completas de Sigmund Freud. Rio de Janeiro: Imago, 1996. vol. 21, p. 38-97.

GARRIDO, Juliana; MOYSÉS, Maria Aparecida Affonso. Um Panorama Nacional de Estudos sobre a Medicalização da Aprendizagem de Crianças em Idade Escolar. In: Conselho Regional de Psicologia de São Paulo; Grupo Interinstitucional Queixa Escolar (org.). Medicalização de Crianças e Adolescentes: conflitos silenciados pela redução de questões sociais a doenças de indivíduos. São Paulo: Casa do Psicólogo, 2011.

GAUDENZI, Paula; ORTEGA, Francisco. O Estatuto da Medicalização e as Interpretações de Ivan Illich e Michel Foucault como Ferramentas Conceituais para o Estudo da Desmedicalização. Interface, v. 16, n. 40, p. 21-34, jan./mar. 2012.

GESSER, Marivete; NUERNBERG, Adriano Henrique; TONELI, Maria Juracy Filgueiras. A contribuição do modelo social da deficiência à psicologia social. Psicologia \& Sociedade, v. 24, n. 3, p. 557-566, 2012.

GOFFMAN, Evering. Stigma: notes on the management of spoiled identity. Englewood Cliffs, New Jersey: PrenticeHall, 1963.

GUARIDO, Renata. A medicalização do sofrimento psíquico: considerações sobre o discurso psiquiátrico e seus efeitos na Educação. Educação e Pesquisa, São Paulo, v. 33, n. 1, p. 151-161, jan./abr. 2007.

GUARIDO, Renata; VOLTOLINI, Rinaldo. O que não tem remédio, remediado está? Educação em Revista. Belo Horizonte, v. 25, n. 1, p. 239-263, abr. 2009.

IÁCONO, Jane Peruzo; PARADA, Eunice Rodrigues Vale. Educação Inclusiva: reflexões após duas décadas de sua implementação no Brasil. In: Seminário Nacional de Pesquisa em Educação, 2020. Disponível em: <https://portaleventos. uffs.edu.br/index.php/SENPE/article/view/14934>. Acesso em: 07 maio 2021.

MARQUEZAN, Rinoldo. O discurso da legislação sobre o sujeito deficiente. Rev. bras. educ. espec., Marília, v. 14, n. 3, p. 463-478, set./dez. 2008.

MEC. Ministério da Educação do Governo Federal do Brasil. Política nacional de educação especial na perspectiva da educação inclusiva, 2008. Disponível em: <http://portal.mec.gov.br/arquivos/pdf/politicaeducespecial.pdf >. Acesso em: 07 maio 2021.

MEIRA, Marisa Eugênia Melillo. Para uma crítica da medicalização na educação. Revista Semestral da Associação Brasileira de Psicologia Escolar e Educacional, v. 16, n. 1, p. 135-142, jan./jun. 2012.

MOYSÉS, Maria Aparecida Affonso. A institucionalização invisível - crianças que não-aprendem-na-escola. Campinas: FAPESP: Mercado de Letras, 2001.

MOYSÉS, Maria Aparecida Affonso; COLLARES, Cecília Azevedo Lima. Dislexia e TDAH: uma análise a partir da ciência médica. In: CONSELHO REGIONAL DE PSICOLOGIA DE SÃO PAULO (org.). Medicalização de Crianças e Adolescentes: conflitos silenciados pela redução de questões sociais a doenças de indivíduos. São Paulo: Casa do Psicólogo, 2010. p. 71-110.

MOYSÉS, Maria Aparecida Affonso; COLLARES, Cecília Azevedo Lima. Medicalização: o obscurantismo reinventado. In: COLLARES, Cecília Azevedo Lima; MOYSÉS, Maria Aparecida Affonso; RIBEIRO, Mônica Cintrão França. Novas capturas, antigos diagnósticos na era dos transtornos. Campinas: Mercado de Letras, 2013. p. 259-270. 
ORGANIZAÇÃO MUNDIAL DA SAÚDE (OMS). Constituição da Organização Mundial da Saúde (OMS/WHO) - 1946. Disponível em: <http://www.direitoshumanos.usp.br/index.php/OMS-Organiza\%C3\%A7\%C3\%A3o-Mundial-da-Sa\%C3\%BAde/constituicao-da-organizacao-mundial-da-saude-omswho.html>. Acesso em: 13 maio 2021.

RESENDE, Flávia Vieira de. Direitos Humanos e Cidadania - Proteção, Promoção e Restauração dos Direitos das Pessoas com Deficiência. Escola de Formação em Direitos Humanos de Minas Gerais - EFDH-MG, Belo Horizonte, v. 10, 2016.

RIBEIRO, Alexandre Simões et al. Psicopatologia na contemporaneidade: análise comparativa entre o DSM-IV e o DSM-V. Fractal: Revista de Psicologia, Niterói, v. 32, n. 1, p. 46-56, jan./abr. 2020.

ROSE, Nikolas. Beyond medicalisation. Lancet, v. 369, n. 9562, p. 700-702, 2007.

SAWAIA, Bader Burihan. O Sofrimento ético-político como categoria de análise da dialética exclusão/Inclusão. In: SAWAIA, Bader Burihan. As artimanhas da exclusão: análise psicossocial e ética da desigualdade social. Petrópolis: Vozes, 2001. p. 97-118.

SOUZA, Warley Carlos de. Transtorno do Déficit de Atenção com Hiperatividade: um caso clínico ou invenção pedagógica?. 2009, Tese. (Doutorado em Educação) - Faculdade de Educação, Universidade de São Paulo, São Paulo, 2009.

SPÍNDOLA, Pablo. O panoptismo de Foucault: uma leitura não utilitarista. Uma leitura não utilitarista. In: XXVI Simpósio Nacional de História - ANPUH, São Paulo, jul. 2011. Disponível em: <http://www.snh2011.anpuh.org/ resources/anais/14/1312590916_ARQUIVO_Artigo-OpanoptismodeFoucault-umaleituranaoutilitarista-Anpuh2011. pdf >. Acesso em: 07 maio 2021.

UNESCO \& MEC-Espanha. Declaração de Salamanca e Linha de Ação: sobre necessidades educacionais especiais. Brasília, DF: CORDE, 1994.

ZORZANELLI, Rafaela Teixeira; ORTEGA, Francisco; BEZERRA JUNIOR, Benilton. Um panorama sobre as variações em torno do conceito de medicalização entre 1950-2010. Ciênc. saúde coletiva, Rio de Janeiro, v. 19, n. 6, p. 1859-1868, jun. 2014.

Data de submissão: 15/05/2021

Data de aceite: $16 / 08 / 2021$ 